\section{Radiation Effects in Uranium-Niobium Titanates}

Pyrochlore is an important actinide host phase proposed for the immobilization of high level nuclear wastes and excess weapon plutonium. ${ }^{11}$ Synthetic pyrochlore has a great variety of chemical compositions due to the possibility of extensive substitutions in the pyrochlore structure..$^{[2]}$ During the synthesis of pyrochlore, additional complex titanate phases may form in small quantities. The response of these phases to radiation damage must be evaluated because volume expansion of minor phases may cause micro-fracturing. In this work, two complex uraniumniobium titanates, $\mathrm{U}_{3} \mathrm{NbO}_{9.8}$ (U-rich titanate) and $\mathrm{Nb}_{3} \mathrm{UO}_{10}(\mathrm{Nb}$-rich titanate) were synthesized by the alkoxide/nitrate route at $1300^{\circ} \mathrm{C}$ under an argon atmosphere. The phase composition and structure were analyzed by EDS, BSE, XRD, EMPA and TEM techniques. An $800 \mathrm{KeV} \mathrm{Kr}{ }^{2+}$ irradiation was performed using the IVEM-Tandem Facility at Argonne National Laboratory in a temperature range from $30 \mathrm{~K}$ to $973 \mathrm{~K}$. The radiation effects were observed by in situ TEM.

At room temperature, the critical amorphization doses $\left(D_{c}\right)$ of U-rich titanate and $\mathrm{Nb}$-rich titanate irradiated by $800 \mathrm{KeV} \mathrm{Kr}^{2+}$ are $4.72 \times 10^{17}(0.10 \mathrm{dpa}$ according to the TRIM-96 calculation) and $5 \times 10^{17}$ ions $/ \mathrm{m}^{2}(0.11 \mathrm{dpa})$, respectively. No significant difference of critical amorphization dose was observed between the U-rich and $\mathrm{Nb}$-rich titanates. The temperature dependences of the critical amorphization doses are shown in Fig. 1. With increasing temperature, the critical amorphization doses increase as a result of dynamic annealing. The critical amorphization temperature for both $\mathrm{Nb}$-rich and U-rich phases is $\sim 933 \mathrm{~K}$.

Above the critical amorphization temperature, full amorphization does not occur, and nanocrystal formation was observed. Fig. 2 shows the microstructure of the U-rich titanate irradiated at $933 \mathrm{~K}$ at an ion dose of $2.5 \times 10^{19}$ ions $/ \mathrm{m}^{2}$. Nanocrystals have a preferred orientation, and the average size is 15 to $20 \mathrm{~nm}$. The microstructure of U-rich titanate irradiated by $1.88 \times 10^{19}$ ions $/ \mathrm{m}^{2} \mathrm{Kr}^{2+}$ at $973 \mathrm{~K}$ is shown in Fig. 3. Nanocrystals with a random orientation were observed.

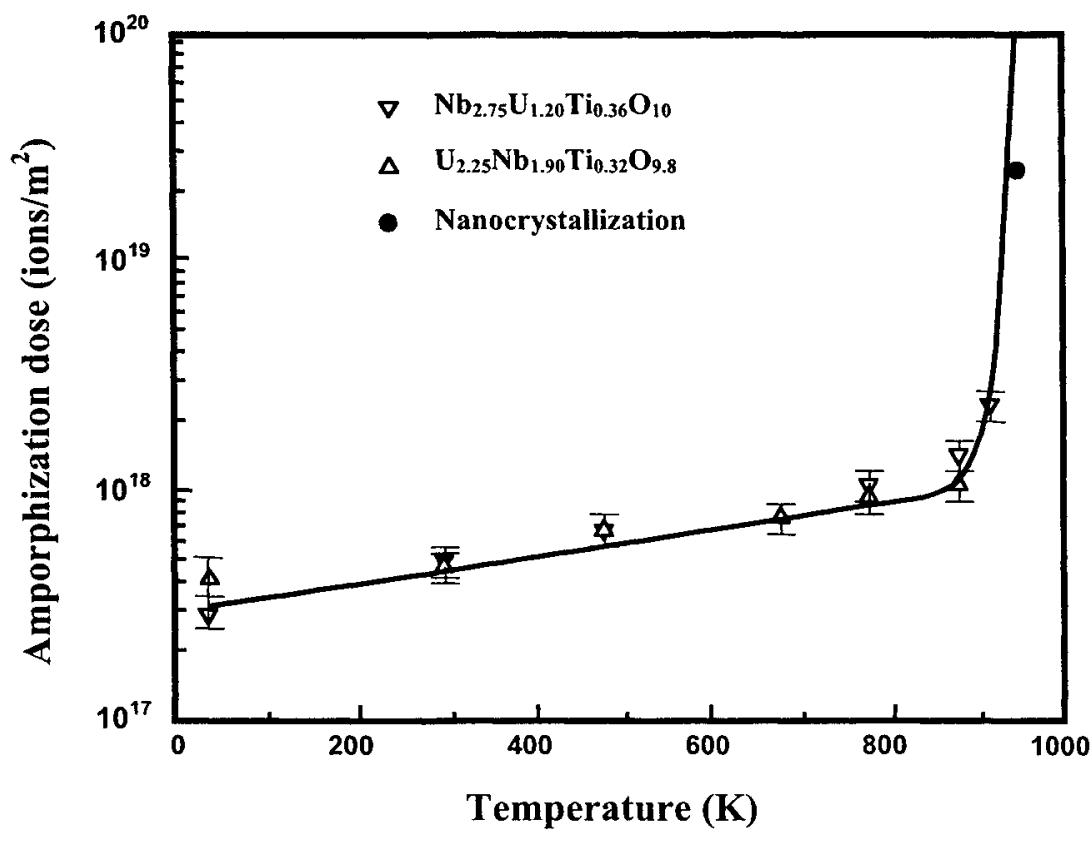

CP532, Plutonium Futures - The Science, edited by K. K. S. Pillay and K. C. Kim, (C) 2000 American Institute of Physics 1-56396-948-3/00/\$17.00
J. Lian,

S. X. Wang,

L. M.Wang,

R. C. Ewing

University of Michigan, Ann Arbor, MI 48109-

2104, USA

Figure 1.

Temperature

dependences of

critical

amorphization

doses of the U-rich

and Nb-rich

titanates irradiated

by $800 \mathrm{KeV} \mathrm{Kr}^{2+}$.

The black dot

denotes the

formation of

nanocrystals at

$933 \mathrm{~K}$. 
Figure 2. (a) Brightfield image; (b) SAD pattern; (c) HRTEM image of U-rich titanate irradiated by $800 \mathrm{KeV} \mathrm{Kr}^{2+}$ at $933 \mathrm{~K}$.

Figure 3. The microstructure of U-rich titanate irradiated by $800 \mathrm{KeV} \mathrm{Kr}^{2+}$ at $973 \mathrm{~K}$ with ion dose of $1.8 \times 10^{19}$ ions $/ \mathrm{cm}^{2}$ : (a) Bright-field image; (b) Dark-field image; (c) HRTEM image.
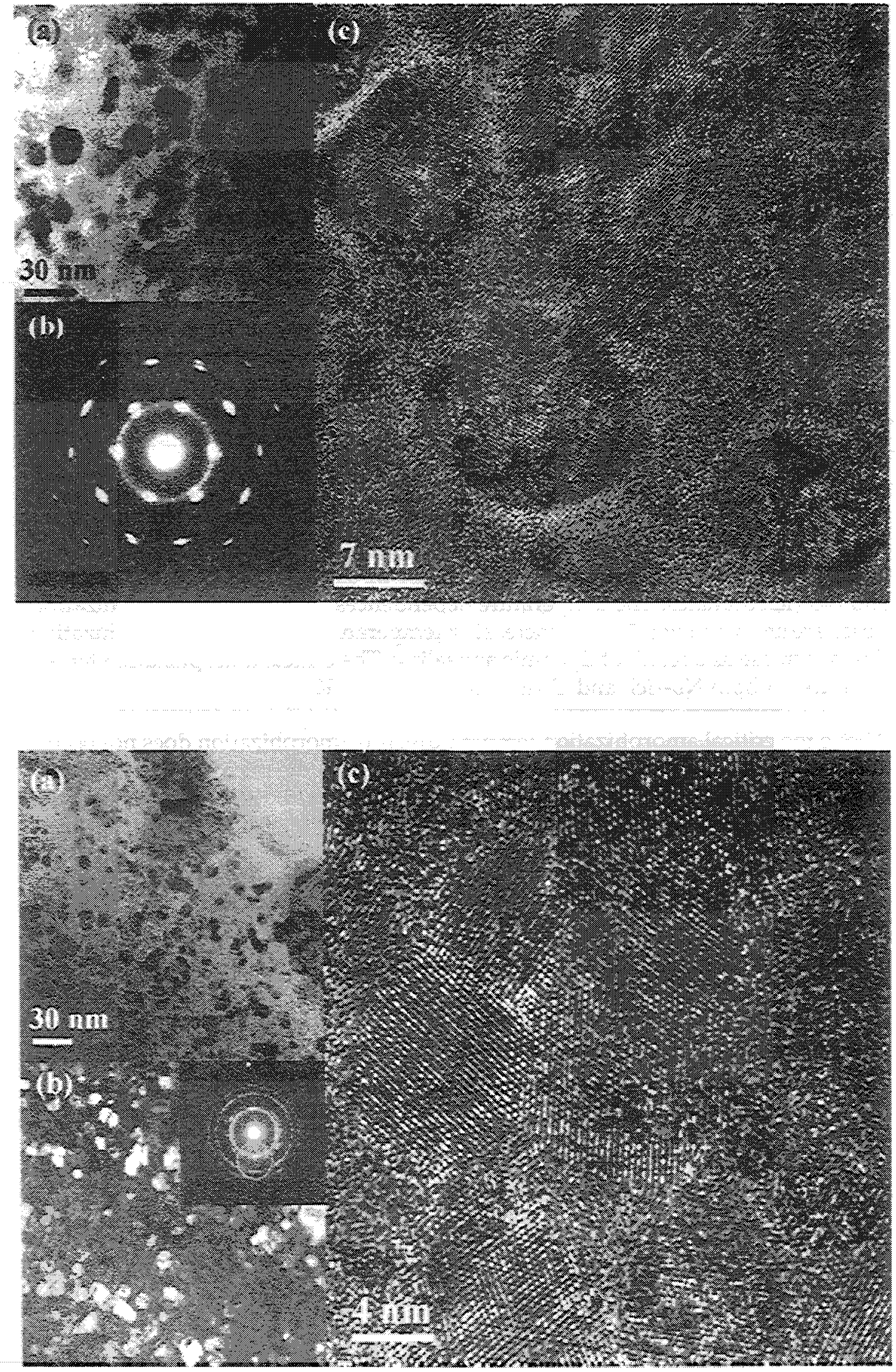
Ion irradiation-induced nanocrystal formation can be the result of competition between amorphization and crystal recovery and recrystallization. ${ }^{|3-5|}$ Epitaxial growth and nucleation-growth are the primary crystal recovery mechanisms during the process of ion irradiation-induced amorphization. Due to the higher energy barrier for the formation of new crystal nuclei, the probability of nucleation-growth is small as compared with that of epitaxial growth. Thus, the epitaxial recrystallization of the highly damaged materials leads to the formation of nanocrystals at $933 \mathrm{~K}$. As a result, nanocrystals show a preferred orientation similar to that of the original crystalline matrix. At a higher temperature, $973 \mathrm{~K}$, the probability of nucleation increases due to the lower quench rate and longer annealing time. Thus, nanocrystals of random orientation can form around these newly formed nuclei. In this case, ion irradiation-induced nucleation-growth of nanocrystals that occurs in heavily damaged crystalline materials at elevated temperature is similar to thermally activated recrystallization in cold-worked metals. ${ }^{[6,7]}$ Epitaxial growth and ion irradiation-induced nucleation-growth both have important effects on the formation and orientation of nanocrystals.

\section{Acknowledgement}

We thank Dr. L. Vance at Australia Nuclear Science and Technology Organization for preparing the samples used in this study.

\section{References}

1. R. C. Ewing, W. J. Weber, W. Lutze, in: E. R. Merz, C. E. Walter (Eds.), Disposal of Weapon Plutonium, Kluwer Academic Publishers, Boston, MA, 1996, 65.

2. B. C. Chakoumakos, R. C. Ewing, Mat. Res. Soc. Symp. 44 (1985) 641

3. L. M. Wang, et al., submitted to Mater. Sci. and Engin. A, 1999.

4. A. Meldrum, et al., Canadian Mineralogist 37 (1999) 207.

5. A. Meldrum, S. J. Zinkle, L. A. Boatner, R. C. Ewing, Nature 395, 3 (1998) 56.

6. L. M. Wang, R. C. Birtcher, R. C. Ewing, Nucl. Instr. and Meth. B 80/81 (1993) 1109.

7. R. C. Birtcher, L. M. Wang, Nucl. Instr. and Meth. B 59 (1991) 966. 